\title{
The promise of panarchy in managed retreat: converging psychological perspectives and complex adaptive systems theory
}

\author{
Kai Greenlees ${ }^{1}$ (D) $\cdot$ Randolph Cornelius $^{2}$ (D) \\ Accepted: 22 April 2021 / Published online: 11 May 2021 \\ (C) The Author(s) 2021
}

\begin{abstract}
This paper interrogates the nature of climate resilience by adopting "panarchy" as a heuristic model to visualize how small-scale processes such as individual environmental risk perceptions are interrelated with broader social and ecological systems to confer community resilience. Thematic analysis of resident interviews from a pilot study conducted in the Rockaways, New York revealed the foundations of environmental risk perceptions and the ways in which they are both a product of and catalyst for social-ecological system (SES) resilience. The debate around managed retreat necessitates a complex systems perspective to promote equitable and just adaptation and transformation while avoiding unintended consequences which often result from single-scale inquiry. Integrating risk perception in the explicit multi-scalar model of panarchy proposes a new way to think about the complex social, economic, political, and psychological processes converging across space and time to confer community resilience and visualize the complexity inherent in relocation. In other words, connecting climate resilience and managed retreat with psychological processes like risk perception emphasizes the importance of implementing multi-scalar interventions to build community adaptive capacity.
\end{abstract}

Keywords Panarchy $\cdot$ Complex adaptive systems (CAS) $\cdot$ Social-ecological system (SES) $\cdot$ Risk perception $\cdot$ Resilience Managed retreat

\section{Prelude: Superstorm Sandy}

The reflections resulting in this paper were inspired by a pilot study conducted on a barrier peninsula called the Rockaways in New York City that form a thin line between the Atlantic Ocean and Jamaica Bay. In 2012, this low-lying peninsula was overwhelmed by "Superstorm" Sandy's 14-foot storm surge, leading to millions of dollars of damage and the death of nine residents. Despite the challenges and trauma caused by Sandy and the development of government buyout programs in the area, the majority of residents have remained in the Rockaways where many (although not all) acknowledge they are just as vulnerable to the next big storm as the day Sandy struck (resident interviews). Why then have not more people

Kai Greenlees

og289@exeter.ac.uk

1 College of Life and Environmental Sciences, University of Exeter, Penryn, UK

2 Psychology Department, Vassar College, Poughkeepsie, NY, USA opted to reduce their vulnerability and mitigate risk exposure by taking adaptive actions such as managed retreat? ${ }^{1}$

\section{The need for a complex systems perspective}

The challenges of climate adaptation in places like the Rockaways can be thought of as a "wicked" problem, problems that are difficult to define, involve multiple disciplines' perspectives, and are inseparable from issues relating to values, equity, and economic and political power (Pritchard and Sanderson 2002). Part of the reason that wicked problems lack simple solutions is due to the complexity and unpredictability of the systems dynamics that define natural hazards (Levin et al. 2012). Angeler et al. (2016) suggest that panarchy, "may be a particularly apt heuristic for framing environmental phenomena that are characterized by complexity...inherent in wicked problems" (p. 226). Panarchy is a conceptual model that describes the ways in

\footnotetext{
${ }^{1}$ The authors acknowledge that we do not necessarily answer this question, but rather present a novel framework for approaching it.
} 
which complex adaptive systems (CAS) involving people and nature are nested within one another, are interdependent and linked across different spatial and temporal scales (Gunderson and Holling 2002).

CAS theory, from which panarchy originates, has trickled down through the computational, natural, and social sciences to find itself at the crux of interdisciplinary study of socialecological systems (SES) (Holland 1995; Lansing 2003; Levin 1998). Importantly, the field of SES has largely been shaped by CAS theory, with SES now being understood as a prime example of a CAS (Levin et al. 2013; Naylor et al. 2020; Preiser et al. 2018; Walker et al. 2004). Viewing a community, such as the Rockaways, through this combined SES and CAS perspective highlights concepts such as leverage points, regime shifts, cross-scale linkages, feedback loops, and nonlinearities (see, for example, Gunderson and Holling 2002; Meadows 1999; Preiser et al.2018; Walker et al. 2004) to understand systems dynamics of resilience, vulnerability, adaptation, and transformation critical to managed retreat.

To date, there has been a lack of integration of psychological processes and perspectives in the CAS, SES, and panarchy literature. Often, the smallest scale of inquiry halts at the community or individual level, with very few cases considering intra-individual processes, despite the growing recognition of the importance of psychological processes in sustainability challenges and climate mitigation and adaptation uptake (Bradley et al. 2020; Grothmann and Patt 2005; IPCC 2012; Nyborg et al. 2016; Swim et al. 2011; Van Valkengoed and Steg 2019). Renowned systems scholar Donella Meadows (1999) identified mindsets as one of the deepest leverage points to transform systems' behavior; thus, it follows that we should be including this scale into any climate adaptation and sustainable transition strategies.

\section{Integrating and reconceptualizing managed retreat}

Recently, Stroink (2020) has detailed how urban and psychological resilience are interdependent by adopting a complex systems approach along with panarchy as a heuristic to model how cross-scalar resilience informs one another. Similarly, Schill et al. (2019) adopt a CAS perspective on human behavior, highlighting that individual behavior creates community contexts, which in term shape behavior iteratively over time, and that this adaptive interaction should inform how policies are prescribed. Our paper seeks to highlight the importance of integrating psychological and complex systems perspectives for effective, equitable, and just managed retreat.

In the managed retreat literature, there has long been an awareness of psychological barriers to relocation, with particular emphasis on risk perception and place attachment (Binder et al. 2015; Costas et al. 2015; Dachary-Bernard and ReyValette 2019; De Dominicis et al. 2015; Solecki and Friedman 2021; Swapan and Sadeque 2020). There has also been a clear awareness of the need for systems and interdisciplinary perspectives when considering managed retreat. For example, Siders (2019) does indeed integrate psychological, institutional, and practical barriers to managed retreat, but does not adopt the kind of explicit multi-scalar framework we are proposing here. Due to the degree of complexity in the challenges posed by coastal threats and managed retreat (see Hino et al. 2017), adopting panarchy as a heuristic to explore and visualize perhaps less obvious cross-scalar effects represents a promising tool to avoid unintended consequences and identify potential leverage points and virtuous cycles for sustainable transformation (Abson et al. 2017; Ahmed et al. 2018; Angeler et al. 2016). However, it is essential to integrate intra-individual psychological processes (e.g., risk perceptions) in this framework as a critical scale that can facilitate or impede managed retreat across multiple scales.

\section{Risk perceptions and panarchy}

Environmental risk perceptions are defined as the perceived probability of being exposed to a natural hazard and the severity of its consequences (Sjöberg et al. 2004; Slovic 1987). While risk perceptions have been relatively neglected in the study of SES resilience, and certainly in the broader CAS literature, they may serve as a catalyst for critical climate adaptation measures such as managed retreat (Dachary-Bernard and Rey-Valette 2019; De Dominicis et al. 2015). Here, we outline themes that underlie community members' perceptions of environmental risk in places such as the Rockaways. We adopt panarchy as a heuristic tool to understand how residents' post-disaster experiences relate to social and ecological forms of resilience to climate change and the adaptive use of managed retreat strategies.

\section{The adaptive cycle}

Resilience, simply defined, is the ability of a system (e.g., individual, community, economy, ecosystem) to persist and bounce back in the face of shocks and stressors (Gunderson 2003). Holling (1986) introduced a conceptual model of adaptive cycles to describe the cyclical nature of systems which alternate between four stages. First, the "exploitation" phase involves rapid development and exponential change. In more sustainable systems, this phase would include adaptation (e.g., investment in nature-based solutions) rather than exploitation (e.g., repeatedly dredging to build back barrier beaches). Second, the "conservation" phase pertains to a slower accumulation and consolidation period, often of resources or knowledge, which tends to reduce a system's flexibility. Third, the "release" phase occurs with the rapid collapse and release of a system's accumulated energy (e.g., from Superstorm Sandy, which decimated much of the 
Rockaways). Fourth, the "reorganization" phase is marked by novel transformation (regime shift) or return to a previous baseline. In resilient and adaptive SESs, reorganization would be rapid and lead to cross-scalar changes that build the adaptive capacity of the system to cope with future natural hazards (e.g., managed retreat) rather than slow recovery or maladaptation (see Fig. 1; Allen et al. 2014; Berkes and Ross 2016; Gunderson and Holling 2002).

\section{Panarchy}

"Panarchy" is the idea that multiple adaptive cycles are hierarchically structured within a system. Within the panarchy model, two cross-scalar interactions known as "remember" and "revolt" facilitate systemic change. The "revolt" process occurs when there is a disruption at a smaller scale that then cascades up to affect larger scales, potentially triggering major crises and leading to system reorganization (Gunderson and Holling 2002). For example, in the community of Breezy Point at the western tip of the Rockaway peninsula, one house with vulnerable electric equipment was flooded with saltwater which then sparked a fire that destroyed hundreds of other houses in the neighborhood. According to one resident,

As the roof shingles were burning, the gale force winds were blowing them off the roof. And it was like meteorites being carried by the wind, and they would land on another house and explode and bang that house caught fire.

"Remember" is a top-down process where larger cycles influence smaller cycles during their reorganization phase, setting the boundaries in which smaller scales operate. For example, instead of considering more adaptive actions (e.g., managed retreat), American society's commitment to development and economic growth has led primarily to the

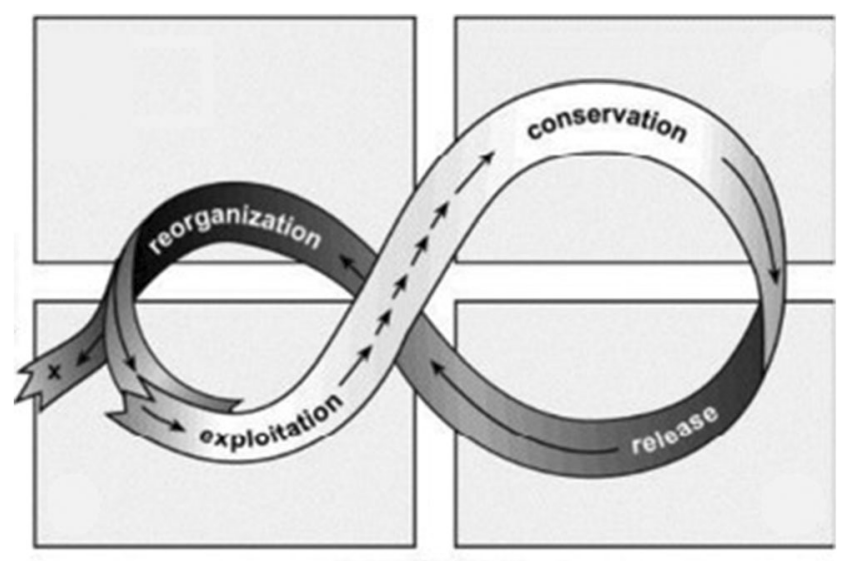

Fig. 1 Adaptive cycle from Panarchy edited by Lance H. Gunderson and C.S. Holling. Copyright $@ 2002$ Island Press. Reproduced by permission of Island Press, Washington, D.C. reconstruction of damaged homes and reinvestment in new developments following Sandy. Via the cross-scalar interactions of "revolt" and "remember," it is evident that each scale of a system is integral to the entire system's resilience, and perturbations within each scale may create a negative or positive cascade throughout the entire system.

Panarchy helps us to visualize how abstract connections from an individual at one time and place (e.g., risk perceptions following disasters) are affected by and have an impact on seemingly disparate domains (e.g., socioeconomic status and climate adaptation) and scales (e.g., community socialecological resilience) via the vertical and horizontal linkages among them. Although resilience, risk perception, flooding, and managed retreat have been extensively studied elsewhere in the disaster literature (see De Dominicis et al. 2015; Lemée et al. 2018; Shao et al. 2018), no studies have applied panarchy as a way to model the interactions among individual risk and resilience to the broader cycles of social-ecological risk and resilience. Research suggests that risk perception is a key driver of decision-making connected to climate adaptation (Bradley et al. 2020; Demuth et al. 2016; Grothmann and Patt 2005; Shao et al. 2018; Sheeran et al. 2014). We argue that adopting the multi-scalar model of panarchy will allow us to go beyond the risk-perception-to-adaptation link to reveal broader connections among individual risk perceptions, community social-ecological resilience, and managed retreat.

As presented in Fig. 2, we have depicted a panarchy of five nested adaptive cycles that interact to coproduce community resilience. The largest adaptive cycle is represented as the environmental system, which sets the foundation for each of the smaller scales that function within it. The Rockaways is a barrier peninsula, and the contexts of each of its subsystems are inherently affected by the impermanence of the landscape. Linked to the environmental system is the political ecology perspective of the social subsystem. In the Rockaways, this scale includes actors across scales. For example, for decades, the City of New York concentrated public housing developments in the east end of the peninsula, increasing the geophysical vulnerability of an already socioeconomically underprivileged population. It was also responsible for instituting the "Build-it-Back" program, enabling many residents in the Rockaways to remain living there following Sandy. Federal offices like FEMA contributed funds and personnel to the clean-up in the immediate aftermath of the storm, facilitating the conditions that allowed for more rather than less coastal development. Furthermore, the Army Corps of Engineers have and continue to play a major role in developing largescale coastal hardening projects (see Army Corps of Engineers' New York-New Jersey Harbor and Tributaries Coastal Storm Risk Management Interim Report, 2019) that enable public and private developers in the area to continue developing in unsustainable areas. In the view of one coastal resident in the area, 


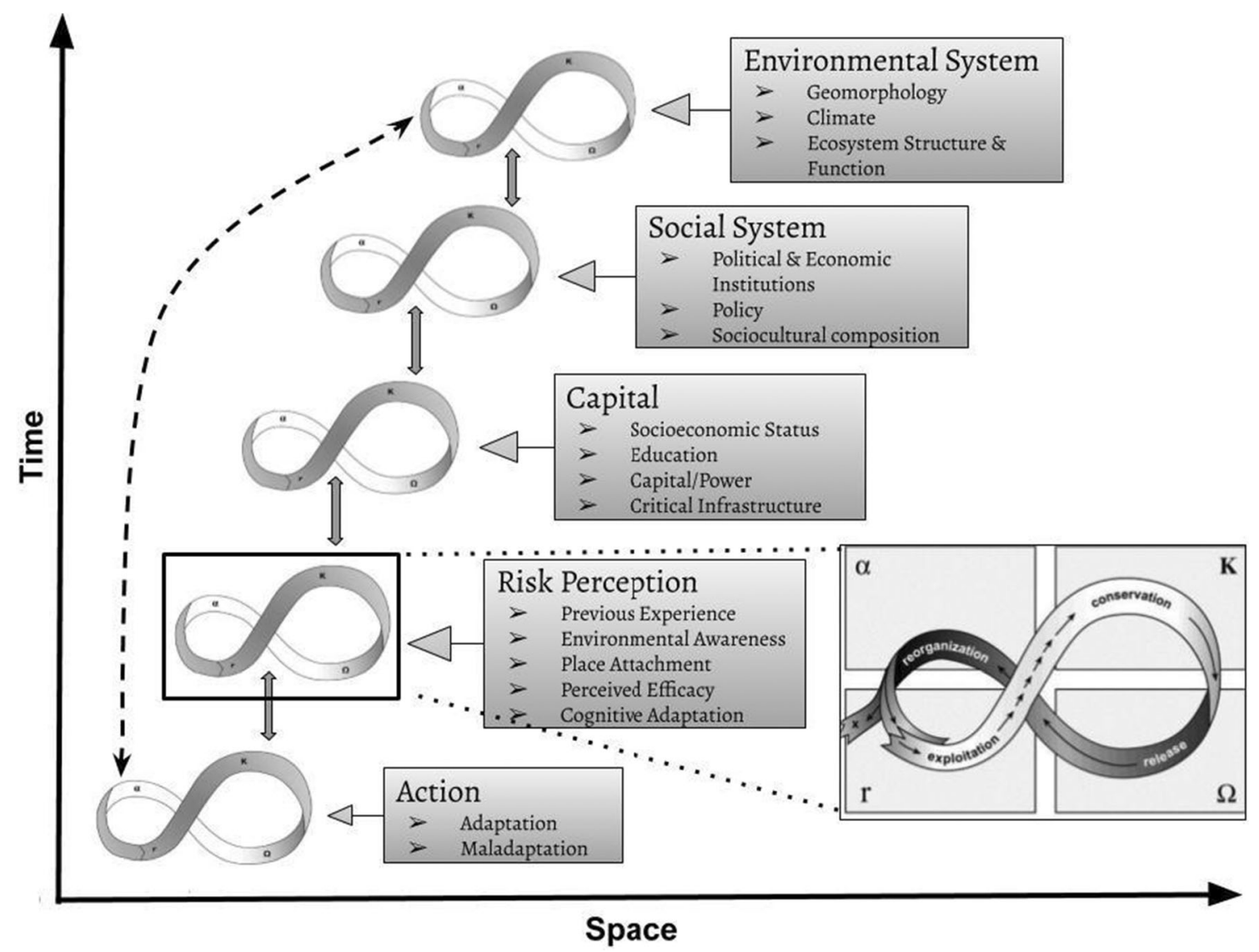

Fig. 2 A model representing the panarchy of community resilience depicting five nested adaptive cycles incorporating risk perception. $X$ axis represents increasing spatial scale, while the $Y$-axis represents increasing time scale. Small double ended arrows represent the revolt and remember processes, while the dotted black arrow represents a feedback loop in which actions at personal levels affect the environmental subsystem. The inset depicts a closer look at the adaptive cycle occurring at each subsystem
Thanks to the federal government they rebuilt it for them. Whether that's the right thing or the wrong thing is a separate issue. But as long as the government's gonna do that, people will rebuild. And people are smarter than you think. They'll take their chances, and they know they'll be fine, and the government will swoop in and build them a new house, so why not enjoy the beach in their view?

Undergirding the social subsystem is a system of capital to which communities have unequal and unstable access. It is clear across the resilience literature and the interviews the first author conducted for a pilot study, however, that while a community's adaptive capacity can be enhanced with increased access to hard capital, it is not the sole determinant of resilience. Soft capital includes education, social capital, and community agency, efficacy, cohesion, and status, which can significantly increase adaptive capacity in addition to economic resources (Babcicky and Seebauer 2017).
Following capital is the primary level of analysis of individual environmental risk perceptions. In order to understand the risk perceptions of Rockaway residents, the first author conducted semi-structured interviews with 12 individuals about their experience with Superstorm Sandy in the Rockaways from which the quotations throughout this article are drawn (see Fig. 2 for the themes that constitute risk perception at an individual level). As revealed in the interviews and literature, risk perceptions trigger the last subsystem, the actions and behaviors that people take to respond to environmental threats (Grothmann and Patt 2005). Those responses can either be adaptive and build community resilience or be maladaptive and erode it.

\section{Risk perception as an adaptive cycle}

Using this model, we argue risk perceptions are not only an outcome of residents' SES but also a potential catalyst to reshape the resilience of a system through adoption of 
transformative adaptation strategies such as managed retreat. If we consider the formation of risk perceptions as an adaptive cycle, we can imagine that, during the growth phase, people learn by gathering information about potential environmental risk. This information-seeking process occurs through formal channels such as education and media or informal channels such as direct experience with disasters or social learning. This growth phase reflects environmental awareness and knowledge and previous experience, themes evident from resident interviews.

During this phase, larger scales affect informationgathering by influencing the way information is organized and digested at an individual level. For example, capital influences what kinds of information people receive. Affluence influences the time people have to collect information, and (unequal) power differentiates people's "competing attention demands" (Lindell and Perry 2012, p. 618), as there may be more pressing risks requiring attention, such as securing food and paying rent. Larger social, political, and economic institutions often frame information in ways to achieve their own goals and thus have an impact on what risk information is most available. For example, New York City simultaneously advocates for building more homeless shelters in the Rockaways while also condemning building in flood zones and buying damaged houses through the "Buyout Program."

As the growth phase progresses and people receive more risk information, the psychological subsystem reaches the conservation phase during which information is internalized and consolidated by individuals and communities as belief and fact. During this phase, perception becomes inflexible, making it difficult to alter risk perceptions even if people are presented with new information. This may reflect confirmation bias, in which people only seek out information that matches their preexisting beliefs, while discounting information that differs from their prior beliefs. This was evident throughout the Rockaways in people who decided not to evacuate prior to the storm or not participate in the buyout program after Sandy, hence influencing one aspect of managed retreat.

Superstorm Sandy signaled a revolt phase, during which there was an extreme event that led to the rapid disruption of accumulated information about environmental risk in the Rockaways. For example, many Rockaway residents who evacuated during Sandy and later returned to find their homes in a "war zone" (resident interview) were forced to deal with the risks of living on the coast in a flood zone. Disruption during this phase is critical to the resilience of any system, as disruption can facilitate opportunities for systemic reorganization and transformation, which in turn has the potential to increase adaptive capacity across scales.

Unfortunately, as seen throughout the history of the Rockaways, disruption and change have been avoided by attempts to engineer stability, rather than adapt to and with it. The same may be said for risk perceptions and managed retreat. People do not cope well with uncertainty and thus seek a form of homeostasis in which risk perceptions do not exceed a subjective level of acceptable threat. During the "reorganization" phase of the risk perception cycle, there are two predominant paths that can in turn influence action. The "remember" connection from larger scales can influence reorganization of one's mindset to return to the preexisting baseline of perceived acceptable levels of risk that existed prior to a disaster. Because, "individuals routinely try to maintain their definition of the environment as 'normal' in the face of evidence that it is not" (Lindell and Perry 2012, p. 619), people are likely to utilize cognitive adaptation (e.g., minimization, denial, risk normalization) to cope with the risk they now know, first-hand, exists.

In this way, risk perceptions may be seen as incredibly resilient, meaning that it takes a great deal of disturbance to exceed a threshold and reach a mental "regime shift" marked by new, perhaps more adaptive, risk perceptions. The restructuring of risk perceptions (e.g., "revolt") following a crisis can have cascading effects throughout the system and may be one of the keys to shifting systems into more adaptive states and decreasing psychological barriers to managed retreat (Siders 2019). If risk perceptions remain elevated following a crisis like Sandy, people are unlikely to be able to cope with the heightened experience of "risk-as-feelings" or hazard-intrusive thoughts reminding them that they live in a vulnerable place (Demuth et al. 2016; Slovic et al. 2004). "If a threat is judged to be real and some unacceptable level of personal risk exists, people are motivated to engage in protective action search" (Lindell and Perry 2012, p. 619). This process moves the risk perception cycle to the action level.

Heightened risk perceptions and the possibility of managed retreat at the individual level, however, are further influenced by larger cycles across the panarchy. Once an individual or community decides to take action against the environmental risk (e.g., sea-level rise, flooding, erosion), they must decide if managed retreat is an effective and available option to mitigate risk exposure, and if they have the personal efficacy to relocate. This is often where social inequalities are not addressed in (re)building and relocating communities in an adaptive manner, particularly following a disaster where recovery needs to be quick. When we do not scrutinize the way our social, political, and economic systems influence and interact with adaptive actions taken to increase community resilience, we may be at risk of producing even more fractured and unequal communities that become vulnerable to future unforeseen "double exposures" (Leichenko and O'Brien 2008) of risk, such as minority displacement to more socially, economically, or environmentally vulnerable areas. Note that in this way the explicit multi-scalar model of panarchy is not only helpful but may reveal how multiple systems coproduce resilience or vulnerability across scales in an effort to avoid unforeseen maladaptation especially when considering the 
complex processes involved in managed retreat. Here it is clear that risk perceptions as an isolated concept, but especially embedded in the multi-scalar model of panarchy, are key to driving the acceptance of managed retreat as an effective adaptation strategy.

\section{Future research and conclusion}

Above all, adopting the complex adaptive systems perspective of panarchy in relation to managed retreat points to the need for (1) adaptive learning across all scales, (2) capitalizing on post-disaster disturbance for adaptive multi-scalar transformation, (3) an awareness of non-linearity and cross-scalar interactions resulting in cascading effects and unintended consequences, and (4) a multi-scalar perspective that integrates and acknowledges intra-individual psychological processes, such as risk perception, as key drivers and leverage points in community SES resilience.

Thus far, panarchy has been predominantly used as a theoretical heuristic with minimal application in management and policy decisions. One exception is Garmestani et al.'s (2020) integration of panarchy as a tool at the onset of an ecosystem management and conservation project in the Great Plains, USA. They report panarchy encouraged translational ecology, enabled novel data visualization, addressed practical approaches to ecosystem management, and has shown promise for policy transformation (Garmestani et al. 2020). For managed retreat, this could involve inclusive community and stakeholder dialog about disaster risk management and importantly developing cross-scalar and complementary policy structures that reduce unintended consequences and maximizes cross-scalar co-benefits. Undoubtedly, the area of applied panarchy implementation and research is growing and will yield exciting outcomes (Gunderson et al. n.d.). We urge forthcoming research and community applications of panarchy to consider the important role and benefits of integrating intra-individual scales and psychological processes in their models.

By adopting the multi-scale approach of panarchy, policy makers and community members alike can see how, or if, their interventions and actions may have exponentially larger crossscalar effects. Additionally, by intentionally integrating a political ecology perspective of social systems, stakeholders can be more mindful of how ingrained inequities within communities amplify vulnerabilities across scales which may have major impacts on such processes as managed retreat. Panarchy is a powerful tool for visualizing how to both help implement managed retreat as an adaptation strategy and help avoid unforeseen cascading consequences, such as minority displacement and gentrification, resulting from complex systems dynamics in coastal communities.

Acknowledgements I would like to thank Vassar College's Department of Environmental Studies for supporting my travels to the Rockaway's to collect interviews for my thesis. I would also like to give thanks to my thesis advisors Dr. Joseph Nevins and special thanks to Dr. Randolph Cornelius who supported the development of this manuscript and becoming my coauthor. Their mentorship and thoughtful comments have been invaluable. I would like to thank the three reviewers for their time spent reading this manuscript. Their comments and insights dramatically improved this final draft. Lastly, I would like to thank the residents of the Rockaways who were kind enough to share their time, stories and experiences with me.

Availability of data and material Transcribed interviews may be obtained by contacting the first author.

Funding The Vassar College Environmental Studies Program for supporting data collection. The University of Exeter for supporting Open Access publication costs.

\section{Declarations}

Ethics approval See IRB and interview consent forms in Supplementary Material.

Conflict of interest The authors declare no competing interests.

Open Access This article is licensed under a Creative Commons Attribution 4.0 International License, which permits use, sharing, adaptation, distribution and reproduction in any medium or format, as long as you give appropriate credit to the original author(s) and the source, provide a link to the Creative Commons licence, and indicate if changes were made. The images or other third party material in this article are included in the article's Creative Commons licence, unless indicated otherwise in a credit line to the material. If material is not included in the article's Creative Commons licence and your intended use is not permitted by statutory regulation or exceeds the permitted use, you will need to obtain permission directly from the copyright holder. To view a copy of this licence, visit http://creativecommons.org/licenses/by/4.0/.

\section{References}

Abson DJ, Fischer J, Leventon J, Newig J, Schomerus T, Vilsmaier U, von Wehrden H, Abernethy P, Ives CD, Jager NW, Lang DJ (2017) Leverage points for sustainability transformation. Ambio 46:30-39. https://doi.org/10.1007/s13280-016-0800-y

Ahmed F, Khan MSA, Warner J, Moors E, Terwisscha Van Scheltinga C (2018) Integrated Adaptation Tipping Points (IATPs) for urban flood resilience. Environ Urban 30:575-596. https://doi.org/10. $1177 / 0956247818776510$

Allen CR, Angeler DG, Garmestani AS, Gunderson LH, Holling CS (2014) Panarchy: theory and application. Ecosystems 17:578-589. https://doi.org/10.1007/s10021-013-9744-2

Angeler DG, Allen CR, Garmestani AS, Gunderson LH, Linkov I (2016) Panarchy use in environmental science for risk and resilience 
planning. Environ Syst Decis 36:225-228. https://doi.org/10.1007/ s10669-016-9605-6

Babcicky P, Seebauer S (2017) The two faces of social capital in private flood mitigation: opposing effects on risk perception, self-efficacy and coping capacity. J Risk Res 20:1017-1037. https://doi.org/10. 1080/13669877.2016.1147489

Berkes F, Ross H (2016) Panarchy and community resilience: sustainability science and policy implications. Environ Sci Pol 61:185-193. https://doi.org/10.1016/j.envsci.2016.04.004

Binder SB, Baker CK, Barile JP (2015) Rebuild or relocate? Resilience and postdisaster decision-making after Hurricane Sandy. Am J Community Psychol 56:180-196. https://doi.org/10.1007/s10464-015-9727-x

Bradley GL, Babutsidze Z, Chai A, Reser JP (2020) The role of climate change risk perception, response efficacy, and psychological adaptation in pro-environmental behavior: a two nation study. J Environ Psychol 68:101410. https://doi.org/10.1016/j.jenvp.2020.101410

Costas S, Ferreira O, Martinez G (2015) Why do we decide to live with risk at the coast? Ocean Coast Manag 118:1-11. https://doi.org/10. 1016/j.ocecoaman.2015.05.015

Dachary-Bernard J, Rey-Valette H (2019) Preferences among coastal and inland residents relating to managed retreat: influence of risk perception in acceptability of relocation strategies. J Envi Management 232:772-780. https://doi.org/10.1016/j.jenvman.2018.11.104

De Dominicis S, Fornara F, Cancellieri UG, Twigger-Ross C, Bonaiuto M (2015) We are at risk, and so what? Place attachment, environmental risk perceptions and preventive coping behaviours. J Environ Psychol 43:66-78. https://doi.org/10.1016/j.jenvp.2015.05.010

Demuth JL, Morss RE, Lazo JK, Trumbo C (2016) The effects of past hurricane experiences on evacuation intentions through risk perception and efficacy beliefs: a mediation analysis. Weather Clim Soc 8: 327-344. https://doi.org/10.1175/WCAS-D-15-0074.1

Garmestani A, Twidwell D, Angeler DG, Sundstrom S, Barichievy C, Chaffin BC, Eason T, Graham N, Granholm D, Gunderson L, Knutson M, Nash KL, Nelson RJ, Nystrom M, Spanbauer TL, Stow CA, Allen CR (2020) Panarchy: opportunities and challenges for ecosystem management. Front Ecol Environ 18:576-583. https://doi.org/10.1002/fee.2264

Grothmann T, Patt A (2005) Adaptive capacity and human cognition: the process of individual adaptation to climate change. Glob Environ Chang 15:199-213. https://doi.org/10.1016/j.gloenvcha.2005.01.002

Gunderson LH (2003) Adaptive dancing: interactions between social resilience and ecological crises. In: Berkes F, Colding J, Folke C (eds) Navigating social-ecological systems: building resilience for complexity and change. Cambridge University Press, London, pp 33-52

Gunderson LH, Holling CS (2002) Panarchy: understanding transformations in human and natural systems. Island Press, Washington, DC

Gunderson L, Allen CR, Garmestani A (n.d.) (In press) Applied panarchy: applications and diffusion across disciplines. Island Press, Washington, DC

Hino M, Field CB, Mach KJ (2017) Managed retreat as a response to natural hazard risk. Nat Clim Chang 7:364-370. https://doi.org/10. 1038/nclimate 3252

Holland JH (1995) Hidden order: how adaptation builds complexity. Addison Wesley Longman Publishing Co., Inc., New York, NY

Holling CS (1986) The resilience of terrestrial ecosystems: local surprise and global change. In: Clark WC, Munn RE (eds) Sustainable Development of the Biosphere. Cambridge University Press, London, pp 292-317

IPCC (2012) Managing the risks of extreme events and disasters to advance climate change adaptation. A special report of Working Groups I and II of the Intergovernmental Panel on Climate Change [(eds.) Field CB, Barros V, Stocker TF, Qin D, Dokken DJ, Ebi KL,
Mastrandrea MD, Mach KJ, Plattner GK, Allen SK, Tignor M, Midgley PM]. Cambridge University Press, Cambridge, UK

Lansing JS (2003) Complex adaptive systems. Annu Rev Anthropol 32: 183-204. https://doi.org/10.1146/annurev.anthro.32.061002.093440

Leichenko R, O'Brien K (2008) Environmental change and globalization: double exposures. Oxford University Press, Oxford

Lemée C, Fleury-Bahi G, Krien N, Deledalle A, Mercier D, Coquet M, Rommel D, Navarro O (2018) Factorial structure of the coastal flooding risk perception and validation of a French coastal flooding risk evaluation scale (CFRES) for non-experts. Ocean Coast Manag 155:68-75. https://doi.org/10.1016/j.ocecoaman.2018.01.030

Levin S (1998) Ecosystems and the biosphere as complex adaptive systems. Ecosystems 5(431):436

Levin K, Cashore B, Bernstein S, Auld G (2012) Overcoming the tragedy of super wicked problems: constraining our future selves to ameliorate global climate change. Policy Sci 45:123-152. https://doi.org/ 10.1007/s11077-012-9151-0

Levin S, Xepapadeas T, Crépin AS, Norberg J, De Zeeuw A, Folke C et al (2013) Social ecological systems as complex adaptive systems: modeling and policy implications. Envi Develop Econ 18:111132. https://doi.org/10.1017/S1355770X12000460

Lindell MK, Perry RW (2012) The protective action decision model: theoretical modifications and additional evidence. Risk Anal 32: 616-632. https://doi.org/10.1111/j.1539-6924.2011.01647.x

Meadows DH (1999) Leverage points: Places to intervene in a system. The Academy for Systems Change. http://donellameadows.org/ archives/leverage-points-places-to-intervene-in-a-system/. Accessed 7 March 2021

Naylor A, Ford J, Pearce T, Van Alstine J (2020) Conceptualizing climate vulnerability in complex adaptive systems. One Earth 2:444-454. https://doi.org/10.1016/j.oneear.2020.04.011

Nyborg K, Anderies JM, Dannenberg A, Lindahl T, Schill C, Schlüter M et al (2016) Social norms as solutions. Science 354:42-43. https:// doi.org/10.1126/science.aaf8317

Preiser R, Biggs R, De Vos A, Folke C (2018) Social-ecological systems as complex adaptive systems. Ecol Soc 23. https://doi.org/10.5751/ ES-10558-230446

Pritchard L, Sanderson SE (2002) The dynamics of political discourse in seeking sustainability. In: Gunderson L, Holling CS (eds) In panarchy: understanding transformations in human and natural systems. Island Press, Washington, DC

Schill C, Anderies JM, Lindahl T, Folke C, Polasky S, Cárdenas JC, Crépin AS, Janssen MA, Norberg J, Schlüter M (2019) A more dynamic understanding of human behaviour for the Anthropocene. Nature Sustainability 2:1075-1082. https://doi.org/10.1038/s41893019-0419-7

Shao W, Gardezi M, Xian S (2018) Examining the effects of objective hurricane risks and community resilience on risk perceptions of hurricanes at the county level in the US Gulf Coast: An innovative approach. Ann Am Assoc Geogr 108:1389-1405. https://doi.org/10. 1080/24694452.2018.1426436

Sheeran P, Harris PR, Epton T (2014) Does heightening risk appraisals change people's intentions and behavior? A meta-analysis of experimental studies. Psychol Bull 140:511-543. https://doi.org/10.1037/ a0033065

Siders AR (2019) Managed retreat in the United States. One Earth 1:216225. https://doi.org/10.1016/j.oneear.2019.09.008

Sjöberg L, Moen BE, Rundmo T (2004) Explaining risk perception: an evaluation of the psychometric paradigm in risk perception research. Rotunde 84:1-39

Slovic P (1987) Perception of risk. Science 236:280-285 
Slovic P, Finucane ML, Peters E, DG MG (2004) Risk as analysis and risk as feelings: some thoughts about affect, reason, risk, and rationality. Risk Anal 24:311-322. https://doi.org/10.1080/24694452. 2018.1426436

Solecki W, Friedman E (2021) At the water's edge: coastal settlement, transformative adaptation, and well-being in an era of dynamic climate risk. Annu Rev Public Health 42:211-232. https://doi.org/10. 1146/annurev-publhealth-090419-102302

Stroink ML (2020) The dynamics of psycho-social-ecological resilience in the urban environment: a complex adaptive systems theory perspective. Front Sustain Cities 2. https://doi.org/10.3389/frsc.2020.00031

Swapan MSH, Sadeque S (2020) Place attachment in natural hazardprone areas and decision to relocate: research review and agenda for developing countries. International Journal of Disaster Risk Reduction 52:101937. https://doi.org/10.1016/j.ijdrr.2020.101937

Swim JK, Stern PC, Doherty TJ, Clayton S, Reser JP, Weber EU, Gifford R, Howard GS (2011) Psychology's contributions to understanding and addressing global climate change. Ameri Psych 66:241-250. https://doi.org/10.1037/a0023220

Van Valkengoed A, Steg L (2019) The psychology of climate change adaptation. Cambridge University Press, London. https://doi.org/10. 1017/9781108595438

Walker B, Holling C, Carpenter S, Kinzig A (2004) Resilience, adaptability and transformability in social-ecological systems. Ecol Soc 9 